\title{
Bone graft incorporation after revision hip arthroplasty in patients with rheumatoid arthritis, seventy eight revisions using bone allografts with or without metal reinforcements
}

\author{
Jacek B. Kowalczewski • Lidia Rutkowska-Sak • \\ Dariusz Marczak • Iwona Slowińska • \\ Radosław Słowiński • Marcin Sibiński
}

Received: 19 December 2012 / Accepted: 11 January 2013 / Published online: 8 February 2013

(C) The Author(s) 2013. This article is published with open access at Springerlink.com

\begin{abstract}
Purpose The aim of the study was to assess bone graft incorporation after revision hip arthroplasty in patients with rheumatoid arthritis (RA).

Methods We report an acetabular reconstruction using impacted, morselized, frozen, radiation sterilized bone allografts in 71 patients suffering from RA. There were sixty-six women and five men at a mean age of 57.5 years. Reconstruction was performed in 78 revision total hip arthroplasties (THAs) for aseptic loosening of acetabular component. The mean follow-up was five years and four months. In 38 cases, a revision was done with use of reinforcement devices. Results In four revised hips (10\%) without reinforcement implants, resorption of the allografts was noticed. All Mueller rings and $50 \%$ of unscrews cages (Link, Howmedica) were revised because of aseptic loosening and bone graft resorption. In all of 17 hips with the Burch-Schneider cage, no measurable migration or bone allografts resorption occurred. There were no major general complications.

Conclusions Acetabular reconstruction with use of morselized, frozen, radiation sterilized bone allografts and the Burch-Schneider cage can be highly successful in managing
\end{abstract}

J. B. Kowalczewski $\cdot$ D. Marczak

Postgraduated Medical Education Centre Orthopeadic Department, Otwock, Poland

L. Rutkowska-Sak • I. Słowińska • R. Słowiński

E.Reicher's Institute of Rheumatology, Warszawa, Poland

M. Sibiński ( $\square)$

Orthopaedic and Paediatric Orthopaedic Clinic,

Medical University of Lodz, ul. Drewnowska 75,

91-002 Łódź, Poland

e-mail: sibinek@poczta.onet.pl massive deficiency of acetabular bone stock in revision hip arthroplasty in RA patients.

\section{Introduction}

The goals of acetabular reconstruction in revision total hip arthroplasty (THA) include restoration of anatomy and normal biomechanics. Unfortunately, there is no unique technique that is likely to provide a solution to restoration of the full spectrum of acetabular deficiency. The acetabular revision of THA in rheumatoid arthritis patients is becoming a big problem, not only because of osteoporotic bone, but also in relation to patient's young age and immunologic response.

The aim of this study was to assess bone graft incorporation after revision hip arthroplasty in patients with rheumatoid arthritis.

\section{Methods}

During the period from February 1998 to February 2003, 71 rheumatoid patients (78 hips) with an acetabular defect after a total, cemented hip arthroplasty were revised. In all patients, the operation was performed due to aseptic loosening of the acetabular component. There were 66 women and five men with a mean age of 57.5 years (range, 26 to 81 years) at the time of the revision arthroplasty. All patients were assessed clinically and radiographically before operation, and were at an average of five years and four months (range, three to eight years) at last follow-up. In 11 patients, the femoral component was revised because of aseptic loosening together with the acetabular cup. 

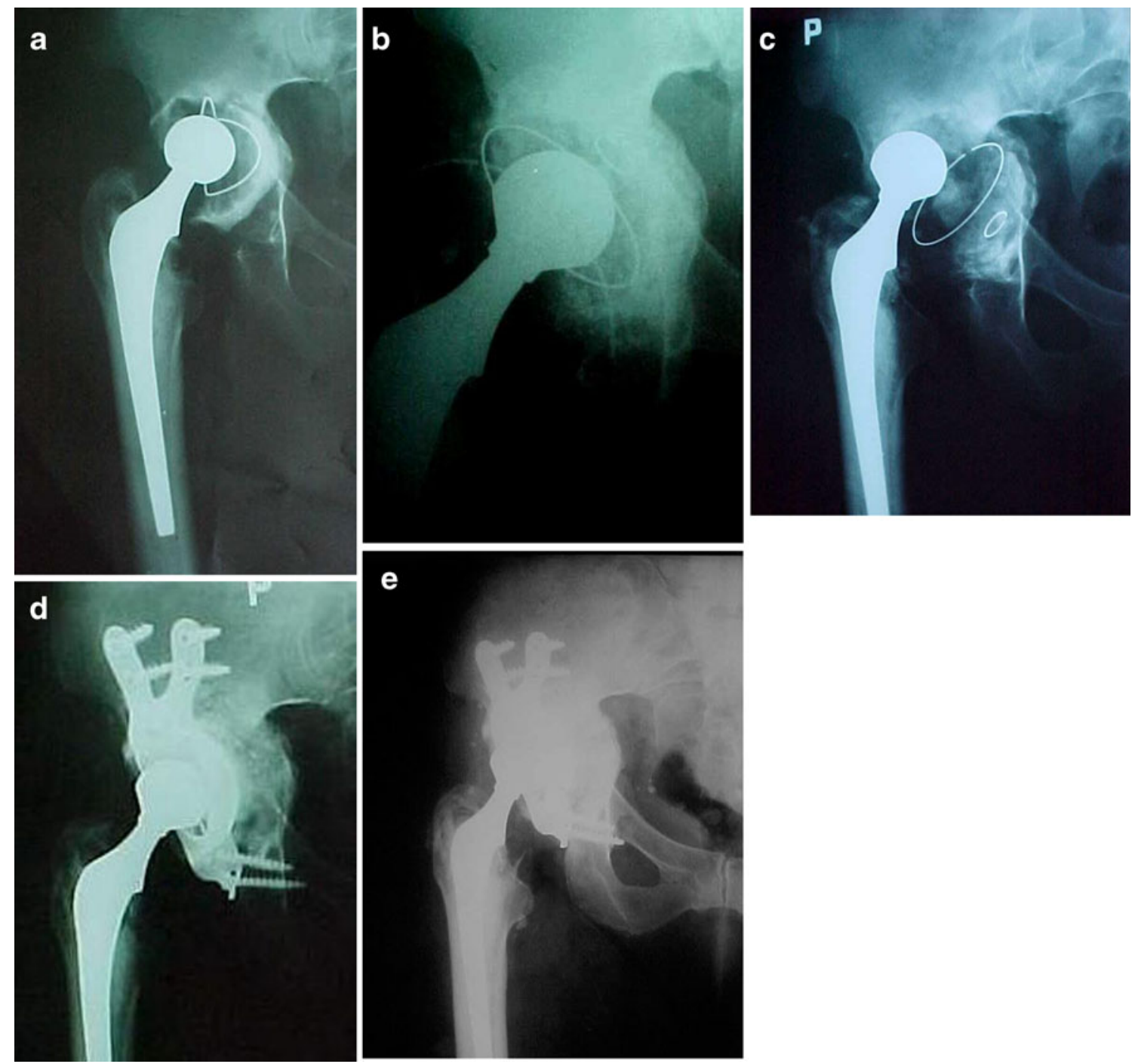

Fig. 1 A radiograph of 46-year-old woman. a cup loosening after six years from implantation. $\mathbf{b}$ after first revision, bone graft and cemented cup was used without reinforcement ring. $\mathbf{c}$ eight months after revision - bone graft resorption and cup loosening. $\mathbf{d}$ six months after next revision Burch- Schneider cage implantation to support bone graft. e after six years, final follow-up - bone graft incorporation, good implant stability
Twenty-one patients received methotrexate at an average dose of $10 \mathrm{mg} / \mathrm{week}$, and 32 received prednisolone at an average dose of $7 \mathrm{mg} /$ day. Eight patients were given methotrexate and prednisolne together. Sulfasalazine was received by three patients (average dose $2 \mathrm{~g}$ /day) and sulfasalazine and prednisolone by seven patients. Nonsteroidal anti-inflammatory drugs (NSAIDs) were used by all patients.

The lateral transgluteal approach was used in 61 hips. When the Burch-Schneider cage was implanted in 17 hips, a posterolateral approach was chosen. In all revisions, the polyethylene acetabular cup was implanted with the use of cement.

The acetabular deficiency was assessed according to the American Academy of Orthopaedic Surgeons (AAOS) classification from A-P radiographs and during operation [1]. Thirty-four hips had type-I deficiency, seven patients had type-II and 37 had type-III deficiency. For bone stock reconstruction, impacted, morselized, radiation-sterilized bone grafts were used in all cases. In 40 hips with a supportive acetabular ring, bone grafts were used according to the procedure described by Sloof et al. (1984) without reconstruction implants [2]. In 38 hips, three types of metal reinforcement rings were used: cages without screws (Link and Howmedica product) in 16 hips, Mueller ring in five hips, and BurchSchnieder cage in 17 hips. The Burch-Schnieder cages were used in the most severe bone deficiency. The type of bone stock deficiency determined the type of metal reinforcement used.

Remodeling and healing of the bone grafts was followed with X-rays after the operation, after six months, and postoperatively every year. The radiographs were evaluated according to DeLee and Charnley [3]. Cup stability on X-Ray was considered to confirm good bone grafts incorporation. The Harris hip score was used to assess the clinical results [4]. 


\section{Results}

On the sequential radiographs taken during postoperative visits, we didn't observe evidence of migration and/or loosening of the cup and bone graft resorption in 61 hips. The average Harris Hip Score for the patients with bone graft incorporation was 72.6 points (range, 45.3 to 85.9 points) at last follow-up.

In four out of 40 hips without metal reinforcement, we found the migration of the cup due to bone graft resorption within six months postoperatively. Three of them were re-operated upon using the Burch-Schneider cage. In one patient, the new bone grafts and the new cup were inserted after removal of the cup, cement and scar tissue.

In eight out of 16 hips, where we used the cages without screws (Link and Howmedica product), bone graft incorporation was observed. The incorporation didn't initially include the full thickness of bone grafts, but the ring remained stable. In the remaining eight hips of this group, we noticed bone graft resorption and loosening of the cage-cup complex.

In all patients (five cases) with the Mueller cage, we noticed bone graft resorption and cage migration within one year after operation. These patients needed another operation.

In all 17 hips with Burch-Schneider cage, all cages remained stable during our observation and bone graft incorporation was noticed within six months (Fig. 1). Five early postoperative dislocations occurred, only in the BurchSchneider cage cases. Two of them underwent revision, and the cup was exchanged and positioned more horizontally. The next two dislocations were treated with closed reduction without cast immobilization. The last one occurred eight months postoperatively, and was related to polyethylene cup loosening from the cage; the cup was replaced.

None of the 17 patients that had revision surgery needed another revision surgery. No future dislocations were noticed. There were no deep or superficial infections and deep thrombosis. No patient in our study had a neurovascular complication. Eleven patients had urinary tract infections due to a catheter. Three patients died. The cause of death was unrelated to the operation.

\section{Discussion}

Revision of the acetabulum in the presence of severe loss of bone stock, especially in rheumatiod arthritis, has become a very difficult surgical problem. Transmission of disease is a potential hazard associated with the use of allograft. Therefore, in our series only morselized, frozen, radiation sterilized bone allografts were used. Experimental data showed only a small radiation influence on physical strength of allograft and on bone morphogenetic protein (BMP) [5-7].
There is not much published data about the results of cup revision with bone grafting exclusively in rheumatoid patients. Schreurs et al. presented 35 consecutive acetabular revisions with bone grafting and cemented cups without any reinforcements. Four of those hips had a repeated revision because of aseptic (three hips) and septic loosening (one hip) [8-10]. Raut et al. reported satisfactory results in 47 hips in 41 patients with RA. He also didn't use any acetabular reinforcement, although $37 \%$ (15 hips) of the sockets showed aseptic loosening. In two of these procedures, the authors used bone grafting only in cases when cavitary or small segmental wall defects of the acetabulum were contained with metal mesh and screw fixation [11]. Mont et al. reported low rate of success at an average of nine years after use of uncemented cups in RA patients. The chance of survival at 108 months was $44 \%$ [12].

In other papers, rheumatoid patients weren't assessed separately $[10,13,14]$. The rate of loosening revised cups due to bone graft resorption in the present study (10\%) is similar or even better to the results found in osteoarthritis (OA) patients, even when our patients used methotrexate (MTX) and steroids [10, 13, 14]. Hori et al. reported almost $20 \%$ of revised cup loosening after using a Kerboull-type acetabular reinforcement device with bulky or impacted allografts. Patients were treated for primary OA and the mean follow-up was 7.5 years (minimum 2.1 years) [14]. Slightly better results were published by Akiyama et al., with the same type of reinforcement ring and bone grafts. Survival rate, calculated using radiological failure or revision, was $87 \%$ at ten years [15], but their patients had less severe acetabular bone defects than patients of Hori et al. [14]. Bohm and Banzhaf reported a rate of $89 \%$ with three reconstruction alternatives in 103 cases that were followed up for 0.3-13 years [16].

In our series, higher rates of bone graft resorption and loosening of rings and cages without primary good screw fixation like Mueller cage was caused by poor primary stabilization. The osteoporotic bone and one fixation point to the ilium bone produced micromovement of cages, which reduced the possibility of bone graft remodelling. In our group of Mueller cages, the loosening and bone graft resorption occurred in all five cases. The studies performed by Schatzeker et al., Zehtner and Ganz or Schreurs et al. illustrated similar poor results [8-10, 17, 18].

In his paper, Markowich compared results from the literature after acetabular reconstruction: cemented or uncemented cups, several types of metal reinforcement, and morselized and structural bone graft. He noticed the best long-term results in Sloof's reconstruction method and when Burch-Schneider cages were used [19]. Also, Bohm and Banzhaf reported better results with the use of the Burch-Schneider than the Harris-Galante cup or the Müller acetabular roof reinforcement ring after 11 years [16]. 
The use of the Burch-Schneider cage type is performed as our reconstruction method of choice when a metal support is needed. The relatively high rate of early dislocation in the beginning in our series of Burch-Schneider cages was caused by our poor technical experience in the fixation position of this cage. Later patients presented with good positioning of the cage, so no additional dislocation took place.

Hamadouche et al. proposed a novel technic for acetabular reconstruction using allograft bone, demineralised bone matrix (DBM) and the Kerboull acetabular device. So far, they have performed nine cases of type III acetabular deficiencies using this technique. No complications have been seen up to now, and gradual bone graft incorporation was observed. Bone remodeling was seen on radiographs by six months [20]. Longer follow-up and larger number of patients are needed to recommend this treatment for standard use.

Use of bone grafts for the reconstruction of the posterior acetabular wall after fracture was reported by Sen et al. After 3.2 months all grafts showed radiological signs of incorporation. At a mean follow-up of 3.34 years, two-thirds of patients had satisfactory radiological results and half of them had satisfactory clinical results [21].

In summary, acetabular reconstruction with the use of morselized, frozen, radiation sterilized bone allografts and acetabular cages with screw fixation to both the ilium and the ischium appears to be a valuable method of managing acetabular revision with bone defects in RA patients. There is no great difference in bone graft incorporation in RA and OA patients according to literature and our data. It is clear that longer-term follow-up will be needed to completely assess this reconstruction procedure.

Open Access This article is distributed under the terms of the Creative Commons Attribution License which permits any use, distribution, and reproduction in any medium, provided the original author(s) and the source are credited.

\section{References}

1. D'Antonio JA, Capello WN, Borden LS (1989) Classification and management of acetabular abnormalities in total hip arthroplasty. Clin Orthop 243:126-137

2. Slooff TJJH, Huiskens R, van Horn J, Lemmens AJ (1984) Bone grafting in total hip replacement fo acetabular protrusion. Acta Orthop Scand 55:593-596

3. DeLee JG, Charnley J (1976) Radiological demarcation of cemented sockets in total hip replacement. Clin Orthop 21:20-32

4. Harris WH (1969) Traumatic arthritis of the hip after dislocation and acetabular fractures: treatment by mold arthroplasty. An endresult study using a new method of result evaluation. J Bone Joint Surg Am 51:737-755
5. Słowińska I, Małdyk P (2012) Losy chorych na reumatoidalne zapalenie stawów leczonych metodą endoprotezoplastyki w obrębie stawów kończyn dolnych. Reumatologia 50:403-409

6. Dziedzic-Gocławska A, Ostrowski K, Stachowicz W, Michalik J, Grzesik W (1991) Effect of radiation sterilization on the osteoinductive properties and the rate of remodeling of bone implants preserved by lyophilization and deep-freezing. Clin Orthop 272:30-37

7. Gross AE, Duncan CP, Garbuz D, Mohamed EM (1999) Revision arthroplasty of the acetabulum in association with loss of bone stock. Instr Course Lect 48:57-66

8. Schreurs BW, Thien TM, de Waal Malefijt MC, Buma P, Veth RP, Slooff TJ (2003) Acetabular revision with impacted morselized cancellous bone graft and a cemented cup in patients with rheumatoid arthritis. J Bone Joint Surg Am 85:647-652

9. Schreurs BW, Luttjeboer J, Thien TM, de Waal Malefijt MC, Buma P, Veth RP, Slooff TJ (2009) Acetabular revision with impacted morselized cancellous bone graft and a cemented cup in patients with rheumatoid arthritis. A concise follow-up, at eight to nineteen years, of a previous report. J Bone Joint Surg Am 91:646-451

10. Schreurs BW, Slooff TJJH, Gardeniers JW, Buma P (2001) Acetabular reconstruction with bone impaction grafting and cemented cup: 20 years experience. Clin Orthop 393:202-215

11. Raut VV, Siney PD, Wroblewski BM (1994) Cemented revision Charnley low-friction arthroplasty in patients with rheumatoid arthritis. J Bone Joint Surg Br 76:909-911

12. Mont MA, Domb B, Rajadhyaksha AD, Padden DA, Jones LC, Hungerford DS (2002) The fate of revised uncemented acetabular components in patients with rheumatoid arthritis. Clin Orthop 400:140-148

13. Rigby M, Kenny PJ, Sharp R, Whitehouse SL, Gie GA, Timperley JA (2011) Acetabular impaction grafting in total hip replacement. Hip Int 21:399-408

14. Hori J, Yasunaga Y, Yamasaki T, Yoshida T, Oshima S, Yamasaki K, Matsuo T, Ochi M (2012) Mid-term results of acetabular reconstruction using a Kerboull-type acetabular reinforcement device. Int Orthop 36:23-26

15. Akiyama H, Yamamoto K, Tsukanaka M, Kawanabe K, Otsuka H, So K, Goto K, Nakamura T (2011) Revision total hip arthroplasty using a Kerboull-type acetabular reinforcement device with bone allograft: minimum 4.5-year follow-up results and mechanical analysis. J Bone Joint Surg Br 93:1194-1200

16. Bohm P, Banzhaf S (1999) Acetabular revision with allograft bone. 103 revisions with 3 reconstruction alternatives, followed for 0.3 13 years. Acta Orthop Scand 70:240-249

17. Schatzker J, Glynn MK, Ritter D (1984) A preliminary review of the Mueller acetabular and Burch-Schneider antiprotrusio support rings. Arch Orthop Trauma Surg 103:5-12

18. Zehntner MK, Ganz R (1994) Midterm results (5.5-10 years) of acetabular allograft recontruction with the acetabular reinforcement ring during total hip revision. J Arthroplasty 9:469-479

19. Markovich GD (1998) Acetabular reconstruction in revision total hip arthroplasty: review of options. Am J Orthop 27:662-670

20. Hamadouche M, Karoubi M, Dumaine V, Courpied JP (2011) The use of fibre-based demineralised bone matrix in major acetabular reconstruction: surgical technique and preliminary results. Int Orthop 35:283-288

21. Sen RK, Tripathy SK, Aggarwal S, Tamuk T (2011) Posterior wall reconstruction using iliac crest strut graft in severely comminuted posterior acetabular wall fracture. Int Orthop 35:1223-1228 